\section{Propagation for the Conservation of Pityopsis ruthii, an Endangered Species from the Southeastern United States}

\author{
Phillip A. Wadl ${ }^{1}$ \\ Department of Entomology and Plant Pathology, University of Tennessee, \\ 2505 E.J. Chapman Drive, 370 Plant Biotechnology Building, Knoxville, \\ TN 37996
}

Timothy A. Rinehart

Thad Cochran Southern Horticulture Research Laboratory, U.S. Department of Agriculture-Agricultural Research Service (USDA-ARS), 810 Highway 26 West, Poplarville, MS 39470

Adam J. Dattilo

Biological Compliance, Tennessee Valley Authority, West Tower 11C-K, 400 West Summit Hill Drive, Knoxville, TN 37902

\author{
Mark Pistrang \\ Cherokee National Forest, U.S. Department of Agriculture-Forest Service, \\ 2800 North Ocoee Street, Cleveland, TN 37312
}

Lisa M. Vito, Ryan Milstead, and Robert N. Trigiano

Department of Entomology and Plant Pathology, University of Tennessee, 2505 E.J. Chapman Drive, 370 Plant Biotechnology Building, Knoxville, TN 37996

Additional index words. bonded fiber matrix, ex situ, in vitro, reintroduction, Ruth's golden aster, seed germination, tissue culture, vegetative propagation

\begin{abstract}
Pityopsis ruthii is an endangered species endemic to the Hiwassee and Ocoee Rivers in Tennessee. As part of a recovery effort focused on $P$. ruthii, vegetative propagation and in vitro multiplication and seed germination techniques were developed. Plants were vegetatively propagated using greenhouse stock plants and wildcollected stems. Rooting occurred with and without auxin treatments but was greatest when $0.1 \%$ indole-3-butyric acid (IBA) talc was applied to the vegetative cuttings; rooting was lowest when flowering stems were used. Pro-Mix BX substrate provided the most consistent rooting. In vitro multiplication was accomplished by the removal of lateral shoots from in vitro-grown plants that were rooted on Murashige and Skoog (MS0) basal medium with 270 clones produced from a single individual after 4 months. Nineteen clones were transplanted and secured with bonded fiber matrix into their natural habitat and 14 survived for 1 year. To avoid genetic swamping of native populations with the introduction of large numbers of genetically identical individuals through clonal propagation, seed-based propagation efforts were explored. Openpollinated seeds were collected, disinfested and germinated, and seedlings established on MS medium. Seeds were submersed in $70 \%$ ethanol for 1 minute and briefly flamed. Seeds were surface-sterilized in a range $[10 \%$ to $50 \%(v / v)]$ Clorox ${ }^{\circledR}$ bleach solutions with vigorous shaking for 20 minutes, rinsed three times in sterile water, and germinated on MS0. Removal of pappus from seeds was required for successful disinfestations, but the bleach concentration was not critical. Successful propagation is a step toward the conservation and recovery of $P$. ruthii and should allow future reintroduction projects.
\end{abstract}

The genus Pityopsis is comprised of seven perennial species and can be found in the eastern United States, southeast Mexico, Bahamas, and Central America (Belize, Guatemala, and Honduras) (Semple, 2006). Pityopsis ruthii (Ruth's golden aster) is listed under the Endangered Species Act (ESA) and occurs only along two small reaches of the Ocoee and Hiwassee Rivers in Polk County, $\mathrm{TN}$. It grows in crevices on exposed phyllite and graywacke rocks that are in and between the river channel and the adjacent forested slopes. The most recent census of Ruth's golden aster populations counted $\approx 11,150$ plants; more than $90 \%$ occur along the Hiwassee River (Tennessee Valley Authority, unpublished data).

Despite its critically imperiled status, as evidenced by its small overall population and narrow geographical range, there has been relatively little applied research focused specifically on species recovery. However, the U.S. Fish and Wildlife Service, which is the federal agency charged with safeguarding

species listed under the ESA, has outlined recovery criteria for Ruth's golden aster that highlight the most critical data gaps and research needs [U.S. Fish and Wildlife Service (USFWS), 1992]. The most recent review of the species status cites a continuing need for better ex situ conservation efforts and additional research focused on restoration of Ruth's golden aster in suitable habitat (USFWS, 2012).

Previous ex situ conservation efforts for Ruth's golden aster have been focused entirely on long-term seed storage (USFWS, 2012). Provided seeds are available and germinate readily, seed-based methods are often the most efficient means for ex situ conservation (Pence, 2011). However, wildcollected Ruth's golden aster seeds often exhibit poor germination and produce seedlings with low vigor (Clebsch and Sloan, 1993; Cruzan, 2001; Farmer, 1977; White, 1977). To overcome the limitations of propagating solely with seed and to provide increased flexibility in ex situ conservation efforts, an in vitro propagation protocol was developed (Wadl et al., 2011). Whereas Wadl et al. (2011) demonstrated the capability to produce plants in vitro, further refinement of current techniques is needed to ensure reliable propagation. Although propagating Ruth's golden aster from seed can be problematic, using seed has the advantage of producing genetically diverse propagules instead of clonal plants, which is essential to minimizing the potential for genetic swamping when producing plants for ex situ conservation and restoration.

Previous efforts to restore Ruth's golden aster in a suitable, unoccupied habitat were unsuccessful. Cruzan and Beaty (1998) performed several experimental plantings, but after two growing seasons, almost $100 \%$ of the transplants had died. The reasons for the experimental failures were not entirely clear, but the investigators recognized the potential for drought stress and soil disturbance to negatively impact reintroduced plants. Although the relative importance of these two factors in the survival of transplanted Ruth's golden aster is unknown, some attempt to mitigate for drought stress and soil disturbance will be integral to restoring the species into a suitable habitat.

The goal of this study was to refine the standard seed germination protocol, in vitro seed germination methodology, and vegetative propagation techniques, including in vitro multiplication of cloned plantlets, to facilitate ex situ conservation and development of a new methodology for restoring Ruth's golden aster into suitable habitat.

\section{Materials and Methods}

Plant material. Clones of $P$. ruthii from an individual plant growing at the University of Tennessee were regenerated from leaf and receptacle tissues using the methods of Wadl et al. (2011) and maintained in vitro and in vivo. Open-pollinated seeds (achenes) were collected from plants growing at the University 
of Tennessee and the Hiwassee and Ocoee Rivers and dried in paper bags at ambient temperature in the laboratory for $3 \mathrm{~d}$. Filled and unfilled seeds were sorted and separated and filled seeds placed into glass vials or seed envelopes, sealed in zip-loc style bags, and stored at $4{ }^{\circ} \mathrm{C}$ until use. Filled seeds are differentiated from unfilled seeds as shown in Figure 1.

Seed germination. In one experiment, 100 filled seeds, each from four different sites on the Hiwassee River, were obtained from the North Carolina Botanical Garden's long-term seed storage and germinated in Feb. 2010. Unfortunately, there are no records for baseline germination rates or treatment of seeds before long-term storage. Seeds from three of the sites were collected in 1994; seeds from the fourth site were collected in 1995. In the second experiment, seeds were collected from three sites on the Ocoee River and one site on the Hiwassee River in Oct. 2010 and germinated in Nov. 2010. In both experiments, seeds were germinated on moist filter paper in petri dishes in the dark between 16 to $24{ }^{\circ} \mathrm{C}$ (Farmer, 1977). Daily observations were made and germinated seeds were established in pots filled with ProMix BX and maintained in a greenhouse.

In vitro seed germination. Preliminary experiments were conducted to germinate seeds in vitro. To disinfest the seeds, 50 seeds were submersed into $70 \%$ ethanol for $1 \mathrm{~min}$ and briefly flamed by passing through an ethanol burner. This was done to remove as much pappus as possible from the seeds. Seeds were then placed into $50-\mathrm{mL}$ conical centrifuge tubes containing $40 \mathrm{~mL}$ of a $20 \%$ $(\mathrm{v} / \mathrm{v})$ Clorox $^{\circledR}$ bleach shaken vigorously for $20 \mathrm{~min}$ and then rinsed three times with sterile water. Individual seeds were placed into $60 \times 60-\mathrm{mm}$ petri plates containing $10 \mathrm{~mL}$ of MS basal medium (Murashige and Skoog, 1962) supplemented with $2 \%(\mathrm{w} / \mathrm{v})$ sucrose, vitamins $\left(2.0 \mathrm{mg} \cdot \mathrm{L}^{-1} \mathrm{~L}-\right.$ glycine, $0.5 \mathrm{mg} \cdot \mathrm{L}^{-1}$ nicotinic acid, $0.5 \mathrm{mg} \cdot \mathrm{L}^{-1}$ pyrodixine, and $1.0 \mathrm{mg} \cdot \mathrm{L}^{-1}$ thiamine $\mathrm{HCl}$ ), $100 \mathrm{mg} \cdot \mathrm{L}^{-1}$ myo-inositol, and solidified with

Received for publication 19 Sept. 2013. Accepted for publication 19 Nov. 2013.

This work was supported by the U.S. Department of Agriculture (Grant \# 58-6404-7-213) and the Tennessee Valley Authority.

Mention of trade names or commercial products in this article is solely for the purpose of providing specific information and does not imply recommendation or endorsement by the University of Tennessee, the Tennessee Valley Authority, or the U.S. Department of Agriculture.

We thank Michael Kunz of the North Carolina Botanical Garden for providing Pityopsis ruthii seeds, Geoff Call of the U.S. Fish and Wildlife Service for assisting in field collection of seeds and vegetative cuttings, and Philip Moore for the photograph in Figure 1B. Plants and seeds were collected under Tennessee Valley Authority Permit \# TE117405-2 and U.S. Fish and Wildlife Service Permit \# TE134817-1.

${ }^{1}$ To whom reprint requests should be addressed; e-mail pwadl@utk.edu.
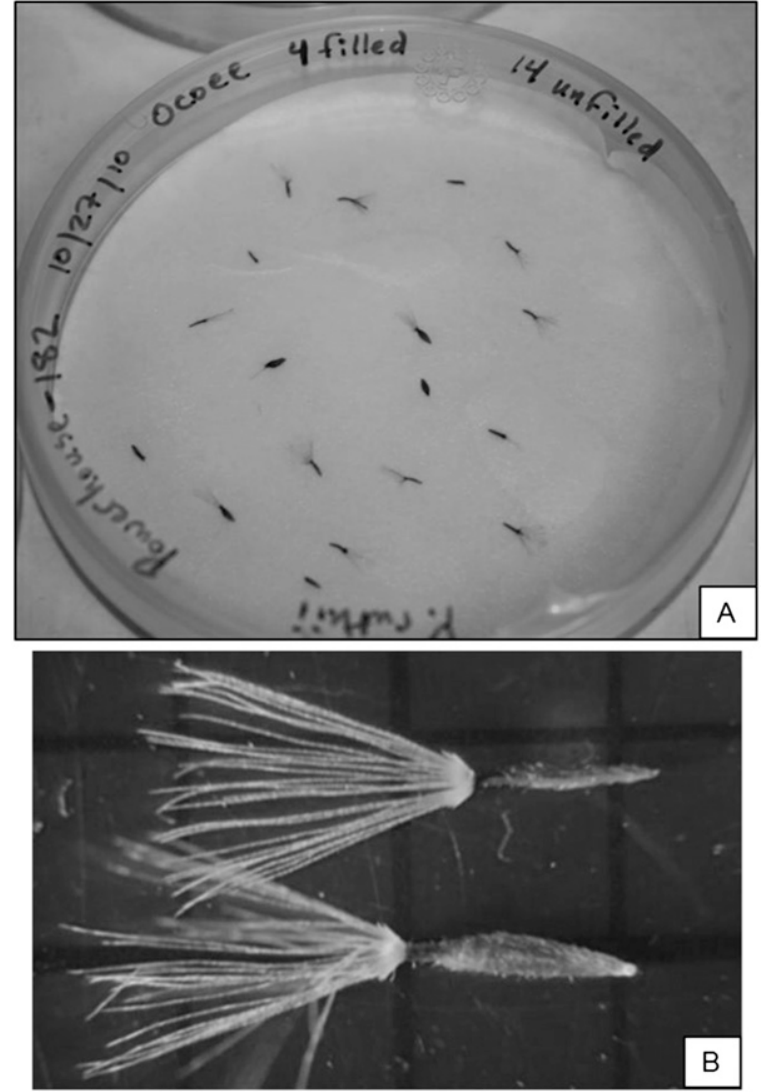

Fig. 1. (A-B) Pityopsis ruthii filled and unfilled seeds (achenes). Filled seeds are distinguished from unfilled seeds by the swollen appearance and contained a mature embryo.

$0.8 \%(\mathrm{w} / \mathrm{v})$ phytagar (Invitrogen, Carlsbad, CA). The $\mathrm{pH}$ of the medium was adjusted to 5.8 before autoclaving at $121{ }^{\circ} \mathrm{C}$ and $103.5 \mathrm{kPa}$ for $20 \mathrm{~min}$. The plates were incubated in the dark between 22 and $25^{\circ} \mathrm{C}$. All seeds were contaminated with unidentified fungal and bacterial growth within $48 \mathrm{~h}$ of culture.

We suspected that the major source of fungal and bacterial contamination in the preliminary experiments originated from the remaining pappus that was attached to the seed. To investigate this hypothesis, we removed all of the pappus from 250 unfilled seeds and left the pappus intact on an additional 250 unfilled seeds. The pappus was removed from each seed by holding it with a pair of forceps while excising the pappus with a razor blade. The seeds were then disinfested in $10 \%, 20 \%, 30 \%, 40 \%$, or $50 \%$ (v/v) Clorox ${ }^{\circledR}$ bleach as previously described. Fifty seeds each from the seed and bleach treatments were placed into a $60 \times 60-\mathrm{mm}$ petri plate containing $10 \mathrm{~mL}$ of MS0. Plates were incubated in the dark between 22 and $25^{\circ} \mathrm{C}$ for 3 weeks and checked daily for contamination.

To investigate the effect of bleach concentration on contamination rate and seed germination, we removed the pappus from 150 filled seeds. Seeds $(n=25)$ were disinfested in the five bleach concentrations and cultured as previously described. A set of 25 seeds was used as a control and treated with sterile water and then germinated on moist filter paper. Individual seeds were placed into a $60 \times 60-\mathrm{mm}$ petri plate containing $10 \mathrm{~mL}$ of MS0. Plates were incubated in the dark between 22 and $25^{\circ} \mathrm{C}$ for 3 weeks and checked daily for contamination and germination. Germination was considered successful after a radicle emerged.

Vegetative propagation. Open-pollinated seeds that were collected from four locations on the Hiwassee River were obtained from the North Carolina Botanical Garden and germinated following the methods of Farmer (1977) and four plants were maintained as stock plants in a greenhouse at the University of Tennessee. Terminal cuttings $(\approx 6.3 \mathrm{~cm})$ from the stock plants were used in preliminary propagation experiments following modifications of Kessler and Keever (2007). Two independent experiments were conducted on 25 Feb. 2011 and 18 Mar. 2011. On the first date, five terminal stems from each stock plant were cut at the base of the stem with scissors. Leaves within $\approx 2.5 \mathrm{~cm}$ of the base of the stem were removed and each stem was placed into water to maintain turgidity. Prepared stems were treated with $0.1 \%$ IBA talc by touching the wet stem to the talc and then stuck into propagation trays containing Pro-Mix BX. Cuttings were misted for $20 \mathrm{~s}$ every $10 \mathrm{~min}$ starting $2 \mathrm{~h}$ after sunrise until $2 \mathrm{~h}$ before sunset for 2 weeks. On the second date, only three stocks plants had sufficient vegetative growth for stem cuttings and were treated the same as the first date.

In Spring 2011, up to five stems were collected from five plants at a Hiwassee River 
location and an Ocoee River location. The terminal stems were removed with a sharp knife and immediately wrapped in wet paper towels and placed into zip-loc-style plastic bags. All stem cuttings were handled as previously described and placed under mist within $12 \mathrm{~h}$ post-collection. The cuttings were checked for roots 2 weeks after the cuttings were stuck.

In 2012, cuttings from multiple stock plants of 15 distinct individuals were used in experiments to determine the effect of growth regulator $(0.1 \%$ IBA) application, growth stage (vegetative vs. flowering) of the stem, and medium (1:1 ratio of Pro-Mix $\mathrm{BX}$ and aged pine bark, Pro-Mix BX, sand, or aged pine bark) on rooting success. Cuttings were stuck into propagation trays or flats of 48-, 32-, or 72-cell packs containing rooting medium and handled as previously described.

In vitro multiplication and restoration. Clones of an individual of $P$. ruthii were regenerated from leaf and receptacle tissue using the methods of Wadl et al. (2011) and in vitro plantlets were transferred to fresh MS0 every 2 weeks. During transfer to fresh media, a lateral stem was accidentally removed from the main stem of an individual. Instead of discarding the stem, it was placed into MS0 for root initiation to assess micropropagation potential. This was repeated with additional lateral stems arising from the mother plantlet and the cloned plantlets over a 4-month period. The lateral shoots were aseptically removed with a scalpel blade and inserted into MS0 for rooting and transferred to fresh MS0 every 2 weeks. Rooted plantlets were transferred to Jiffy-7 Peat Pellets and acclimated to ambient greenhouse conditions and then to natural environmental conditions in March of 2011. To test the survival of acclimated plants in their natural habitat, 19 clones were transplanted into unoccupied suitable habitat on the Ocoee River. Immediately before transplanting, the peat-based medium was gently removed from each clone and planted into crevices that were backfilled with soil that was collected from the location. Because a suitable habitat is defined by extreme high temperatures, drought, and scouring water associated with heavy rainfall and flood flows, we applied bonded fiber matrix over the crevice. Bonded fiber matrix (BFM) is a material comprised of polymers and wood fibers used in the erosion control industry to stabilize soil and to establish vegetation on disturbed sites. When applied as a slurry, the material adheres to itself and the substrate to which it is applied. Plant growth was monitored throughout the growing season and again in the next spring.

Ex situ conservation. Plants derived from all propagation methods tested have been planted into field plots at the Thad Cochran Southern Horticulture Research Laboratory (USDA-ARS, Poplarville, MS) and the University of Tennessee Forest Resources AgResearch and Education Center (Oak Ridge, $\mathrm{TN}$ ) in 2012 to initiate ex situ conservation.

Statistical analyses. Observations from seed germination and vegetative propagation were gathered to frequency tables and analyzed with Fisher's exact test in PROC FREQ (SAS Version 9.3; SAS Inst., Cary, NC).

\section{Results}

Seed germination. In the experiment using the seeds obtained from long-term storage, germination was extremely low $(0 \%$, $1 \%$, and $0.5 \%$ ) for the three sites collected in 1994, whereas the site collected in 1995 germination was $38 \%$. Reduced vigor was observed for all seedlings and only four plants survived longer than 11 months. These four plants have been used in successful vegetative propagation experiments in 2011 and 2012.

In the experiment using seed collected in 2010, the percentage of filled and unfilled seeds was calculated before germination. For the Ocoee River sites, $28 \%$ of the Lone Rock $(\mathrm{n}=162)$ seed was filled, $22 \%$ of the Powerhouse $(\mathrm{n}=18)$ seed was filled, and $52 \%$ of the Tablesaw $(n=322)$ seed was filled. None of the filled seeds or the unfilled seeds from the Lone Rock or Tablesaw sites germinated, but $100 \%$ of the filled seed and $0 \%$ of the unfilled seed from the Powerhouse site germinated. One month after germination, none of the seedlings produced true leaves and all exhibited reduced vigor similar to that of the seeds from long-term storage. For the seed collected from the Hiwassee River site $(\mathrm{n}=$ 575 ), $9 \%$ of the seeds were filled and only $17 \%$ of these germinated, and none of unfilled seeds germinated. Vigor of these seedlings was similar for those from the Hiwassee River.

In vitro seed germination. The effectiveness in disinfesting seeds was determined by the proportion of the seeds that were not contaminated after bleach treatment and pappus removal. A total of 500 unfilled seeds were evaluated and the distribution of contamination for the five bleach concentrations and pappus removal are reported in Table 1 . The difference of not contaminated seeds between bleach levels was significant $(P=$ $0.0118)$ and highly significant $(P<0.0001)$ for the pappus removal treatment and the interaction between bleach level and pappus. When the pappus was left intact, only $2.4 \%$ of the seeds were free from bacterial or fungal contamination regardless of the bleach treatment compared with $74.8 \%$ of the seeds that were not contaminated when the pappus was removed. However, when the pappus was removed from filled seeds $(n=150)$, the bleach concentration did not have a significant effect on contamination rate or germination (Table 2) and suggests internal contamination of seeds with either bacteria or fungi. We did not examine the differences in growth between treatments, although variation among all seedlings was observed (Fig. 2). In general, the in vitro seedlings were larger than seedlings that were grown exclusively on Pro-Mix BX.

Vegetative propagation. All stem cuttings rooted within 2 to 3 weeks in the vegetative propagation experiments and Table 3 summarizes the effect of IBA, growth stage, and medium on rooting. Application of a $0.1 \%$ IBA talc to the cuttings resulted in $100 \%$ rooting compared with $87.5 \%$ in the control (no IBA). The stage of growth of the donor plants had a highly significant $(P<0.0001)$ effect on rooting success of the cuttings. When stems were used from plants that were

Table 1. Frequencies of contaminated and surfaced sterilized unfilled seeds of Pityopsis ruthii for different treatment parameters as calculated from $P$ values of Fisher's exact test using Proc Freq (SAS 9.3; SAS Institute, Cary, NC).

\begin{tabular}{|c|c|c|c|}
\hline \multirow[b]{2}{*}{ Parameter ( $P$ value $)$} & \multicolumn{2}{|c|}{ Number of seeds } & \multirow[b]{2}{*}{ Total } \\
\hline & Contaminated (\%) & Not contaminated $(\%)$ & \\
\hline \multicolumn{4}{|c|}{ Bleach $(\%)(P=0.0118)$} \\
\hline 10 & $72(72)$ & $28(28)$ & 100 \\
\hline 20 & $67(67)$ & $33(33)$ & 100 \\
\hline 30 & $63(63)$ & $37(37)$ & 100 \\
\hline 40 & $53(53)$ & $47(47)$ & 100 \\
\hline 50 & $52(52)$ & $48(48)$ & 100 \\
\hline Total & $307(61.4)$ & $193(38.6)$ & 500 \\
\hline \multicolumn{4}{|l|}{ Pappus $(P<0.0001)$} \\
\hline Pappus intact & $244(97.6)$ & $6(2.4)$ & 250 \\
\hline Pappus removed & $63(25.2)$ & $187(74.8)$ & 250 \\
\hline Total & $307(61.4)$ & $193(38.6)$ & 500 \\
\hline \multicolumn{4}{|c|}{$10 \%$ bleach*pappus $(P<0.0001)$} \\
\hline Pappus intact & $50(100)$ & $0(0)$ & 50 \\
\hline Pappus removed & $22(44)$ & $28(56)$ & 50 \\
\hline \multicolumn{4}{|c|}{$20 \%$ bleach $*$ pappus $(P<0.0001)$} \\
\hline Pappus intact & $48(96)$ & $2(4)$ & 50 \\
\hline Pappus removed & $19(38)$ & $31(62)$ & 50 \\
\hline \multicolumn{4}{|c|}{$30 \%$ bleach*pappus $(P<0.0001)$} \\
\hline Pappus intact & $49(98)$ & $1(2)$ & 50 \\
\hline Pappus removed & $14(28)$ & $36(72)$ & 50 \\
\hline \multicolumn{4}{|c|}{$40 \%$ bleach $*$ pappus $(P<0.0001)$} \\
\hline Pappus intact & $49(98)$ & $1(2)$ & 50 \\
\hline Pappus removed & $4(8)$ & $46(92)$ & 50 \\
\hline \multicolumn{4}{|c|}{$50 \%$ bleach*pappus $(P<0.0001)$} \\
\hline Pappus intact & $48(96)$ & $2(4)$ & 50 \\
\hline Pappus removed & $4(8)$ & $46(92)$ & 50 \\
\hline Total & $307(61.4)$ & $193(38.6)$ & 500 \\
\hline
\end{tabular}


Table 2. Frequencies of contaminated and surface-sterilized seeds and germinated filled seeds with pappus removed of Pityopsis ruthii for different treatment parameters as calculated from $P$ values of Fisher's exact test using Proc Freq (SAS 9.3; SAS Institute, Cary, NC).

\begin{tabular}{|c|c|c|c|}
\hline \multirow[b]{2}{*}{ Parameter ( $P$ value $)$} & \multicolumn{2}{|c|}{ Number of seeds } & \multirow[b]{2}{*}{ Total } \\
\hline & Contaminated (\%) & Not contaminated $(\%)$ & \\
\hline \multicolumn{4}{|c|}{$\overline{\text { Bleach }(\%)(P=0.9906)}$} \\
\hline 10 & $8(32)$ & $17(68)$ & 25 \\
\hline 20 & $8(32)$ & $17(68)$ & 25 \\
\hline 30 & $7(28)$ & $18(72)$ & 25 \\
\hline 40 & $7(28)$ & $18(72)$ & 25 \\
\hline 50 & $6(24)$ & $19(72)$ & 25 \\
\hline \multirow[t]{3}{*}{ Total } & $36(28.8)$ & $89(71.2)$ & 125 \\
\hline & \multicolumn{2}{|c|}{ Number of seeds } & \\
\hline & Germinated (\%) & Not germinated $(\%)$ & \\
\hline \multicolumn{4}{|c|}{ Bleach $(\%)(P=0.1835)$} \\
\hline 0 & $18(72)$ & $7(28)$ & 25 \\
\hline 10 & $23(92)$ & $2(8)$ & 25 \\
\hline 20 & $24(96)$ & $1(4)$ & 25 \\
\hline 30 & $23(92)$ & $2(8)$ & 25 \\
\hline 40 & $23(92)$ & $2(8)$ & 25 \\
\hline 50 & $22(88)$ & $3(12)$ & 25 \\
\hline Total & $133(88.7)$ & $17(11.3)$ & 150 \\
\hline
\end{tabular}
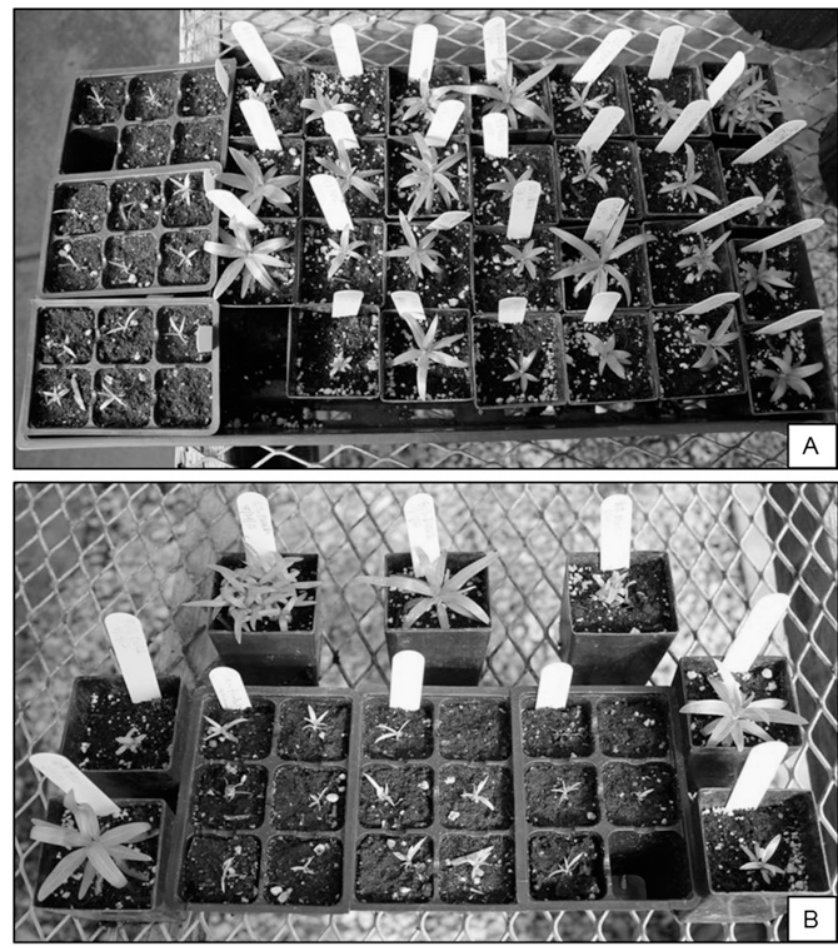

Fig. 2. (A-B) Comparison of in vitro and in vivo-derived seedlings $98 \mathrm{~d}$ after start of experiment. Seedlings growing in individual pots were germinated and grown in vitro on Murashige and Skoog medium for $71 \mathrm{~d}$ before transplanting to Pro-Mix BX and seedlings growing in packs of six were germinated on moistened filter paper and immediately planted into Pro-Mix BX.

vegetatively growing, $84.8 \%$ rooted compared with $5.4 \%$ of the stems that were collected from plants that were flowering. The effects of rooting medium in rooting of vegetative cuttings was highly significant $(P<0.0001)$. None of the cuttings rooted when they were stuck into either aged pine bark or sand; however, $72.5 \%$ of cuttings rooted in a 1:1 ratio of Pro-Mix BX to aged pine bark compared with $93.1 \%$ of the cuttings stuck into Pro-Mix BX. Regardless of the treatment, those cuttings that did produce adventitious roots did so within 2 weeks of initiation.

In vitro multiplication and restoration. Micropropagation of individual lateral shoots from a single clone began on 10 Nov. 2010 and 4 months later, 270 clones were successfully produced (Fig. 3). Of these clones, 117 were transferred to soilless medium and acclimated to both greenhouse and natural conditions over a 3-week period. The remaining clones were maintained in vitro $(\mathrm{n}=153)$. A preliminary restoration experiment was initiated on 24 Mar. 2011 and used BFM to secure 19 clones of $P$. ruthii into a suitable habitat at a location on the Ocoee River (Fig. 4). Two sites were chosen and 10 and nine plants were planted at each site, respectively. Mortality was observed only at the site with nine plants. At $47 \mathrm{~d}$ after planting (DAP), survival was $66.7 \%$ (six of nine), at 124 DAP, survival was $55.6 \%$ (five of nine), and at 181 DAP, survival was $44.4 \%$ (four of nine). After one growing season (377 DAP), preliminary results are positive with $73 \%$ total survival across the two planting sites. One site exhibited $100 \%$ survival (10 of 10$)$, whereas only four of nine plants $(44.4 \%)$ survived at the second site. The remaining 98 clones that were acclimated to natural conditions were used in vegetative propagation experiments or planted into the field to establish an ex situ collection.

Ex situ conservation. Ten clones each of five $P$. ruthii genotypes were planted into the field at the Thad Cochran Southern Horticultural Laboratory (Poplarville, MS) in Spring 2012. The plants were not irrigated during the Summer of 2012 and flowered in Fall 2012 and all plants were alive and had new growth in Spring 2013. In Fall 2012, 10 clones each of 13 P. ruthii genotypes were planted into the field at the University of Tennessee Forest Resources AgResearch and Education Center (Oak Ridge, TN) without irrigation. Plant survival was greater than $75 \%$ through Summer 2013.

\section{Discussion}

Target 8 of the Global Strategy for Plant Conservation has a stated goal of "At least 75 percent of threatened plant species in ex situ collections, preferably in the country of origin, and at least 20 percent available for recovery and restoration programmes of them included in recovery and restoration programs" (Sharrock, 2012). As Pence (2011) noted, Target 8 encompasses the following two goals of ex situ conservation: propagation of plants for recovery of wild populations and to provide backup collections of plants for restorations should wild plants be lost. Seed-based methods are the most efficient for ex situ preservation provided there is enough seed available and germination procedures are adequate (Pence, 2011). Additionally, preservation can be accomplished using propagation by cuttings or other vegetative methods. Conservation and restoration of Ruth's golden aster can be achieved by implementing ex situ conservation strategies such as conventional and in vitro propagation.

Although seed-based methods are noted as the most efficient for preservation and propagation of endangered species (Pence, 2011), seed production and viability of Ruth's golden aster are variable. Farmer (1977) found that $\approx 5 \%$ of randomly selected seeds were filled when collected from plants along the Hiwassee River in 1974 and the reported viability of the seeds was high, although this was not quantified. White (1977) estimated that $18 \%$ of the seeds per flower are filled with 
a mature embryo. Clebsch and Sloan (1993) studied seed production and germination of Ruth's golden aster and concluded that the proportion of filled seed was highly variable, but the overall viability of the seeds was $68.5 \%$. Viability of filled seeds collected from five locations each from the Hiwassee and Ocoee Rivers was $38.7 \%$ and viability was higher for seeds from the Ocoee River (Cruzan, 2001). Cruzan (2001) also reported highly variable rates of seed viability with locations ranging from $14 \%$ to $87 \%$. Our results are in agreement with the findings of Clebsch and Sloan (1993) and Cruzan (2001) with regard to seed viability. We found that viability from three locations on the Ocoee River ranged from $0 \%$ to $100 \%$ and was $17 \%$ from a location on the Hiwassee River. Viability of the seeds from long-term storage ranged from $0 \%$ to $38 \%$ and this could be a result of the effects of long-term storage or

Table 3. Frequencies of rooted and not rooted stem cuttings of Pityopsis ruthii for different treatment parameters as calculated from $P$ values of Fisher's exact test using Proc Freq (SAS 9.3; SAS Institute, Cary, NC).

\begin{tabular}{|c|c|c|c|}
\hline \multirow[b]{2}{*}{ Parameter ( $P$ value $)$} & \multicolumn{2}{|c|}{ Number of stem cuttings } & \multirow[b]{2}{*}{ Total } \\
\hline & $\overline{\text { Rooted (\%) }}$ & Not rooted $(\%)$ & \\
\hline \multicolumn{4}{|l|}{ Growth regulator $(P=0.0062)^{\mathrm{z}}$} \\
\hline Yes & $64(100)$ & $0(0)$ & 64 \\
\hline No & $56(87.5)$ & $8(12.5)$ & 64 \\
\hline Total & $120(93.8)$ & $8(6.2)$ & 128 \\
\hline \multicolumn{4}{|l|}{ Growth stage $(P<0.0001)^{\mathrm{y}}$} \\
\hline Vegetative & $862(84.8)$ & $154(15.2)$ & 1016 \\
\hline Flowering & $22(5.2)$ & $404(94.8)$ & 426 \\
\hline Total & $884(61.3)$ & $558(38.7)$ & 1442 \\
\hline \multicolumn{4}{|l|}{ Media $(P<0.0001)^{\mathrm{x}}$} \\
\hline 1:1 (Pro-Mix BX:pine bark) & $174(72.5)$ & $66(27.5)$ & 240 \\
\hline Aged pine bark & $0(0)$ & $16(100)$ & 16 \\
\hline Pro-Mix BX & $752(93.1)$ & $56(6.9)$ & 808 \\
\hline Sand & $0(0)$ & $16(100)$ & 16 \\
\hline Total & $926(85.7)$ & $154(14.3)$ & 1080 \\
\hline
\end{tabular}

variability inherent in the collected seeds. There is no way to determine this because there are no records for baseline germination rates or treatment of seeds before long-term storage. Additionally, there is no evidence of dormancy in seeds of Ruth's golden aster. Clebsch and Sloan (1993) and Farmer (1977) reported seed germination rates of $90 \%$ or greater for seeds that were collected and germinated within 3 months of harvest. However, seed viability declined to $75 \%$ within 6 months in seeds that were stored in glass containers at $3{ }^{\circ} \mathrm{C}$ (Farmer, 1977). Regardless, it appears that seed viability is highly variable between river systems and year of collection.

Cruzan (2001) suggested that inbreeding and habitat quality may affect seed viability and vigor. Population genetics studies are limited for $P$. ruthii, thus limiting any interpretation for the role of genetic diversity on seed germination and longevity. An allozyme marker study concluded that there was little gene flow among the Hiwassee and Ocoee River populations and that gene diversity within the populations was the result of subpopulations (Sloan, 1994); however, broad comparisons of the data to other studies should be avoided because only two polymorphic loci were resolved. The limited number of loci used in this study highlights one of the well-known limitations of allozymes (Fritsch and Rieseberg, 1996) and can potentially underestimate genetic diversity and lead to inappropriate conservation recommendations in rare plant species (Les et al., 1991). Chloroplast DNA (cpDNA) markers revealed that the Ocoee and Hiwassee River populations are genetically divergent and that gene flow through seed dispersal is limited (Cruzan and Estill, 2001). However, cpDNA markers can be of limited usefulness for studies of population structure resulting from the low levels of intraspecific variation in chloroplast genomes (Cruzan, 1998).

Closure of dams on the Hiwassee River and Ocoee Rivers resulted in significant changes to the hydrology of both rivers where the plant occurs, although it is not known what effect damming of the river and augmented flows have on seed recruitment of Ruth's golden aster. Seed distribution is thought be adapted for water dispersal or rolling around on the rock substrate until a seed is lodged into a suitable crevice or blown into the water by the wind (Clebsch and Sloan, 1993). Germination of seedlings in wild populations has been observed and the mortality was higher than $90 \%$ after 1 year (Clebsch and Sloan, 1993). The effects of habitat loss on small plant populations can result in the loss of genetic variation through random genetic drift and lead to increased selfing and mating among related individuals (Honnay and Jacquemyn, 2007). Further studies are needed to determine if Ruth's
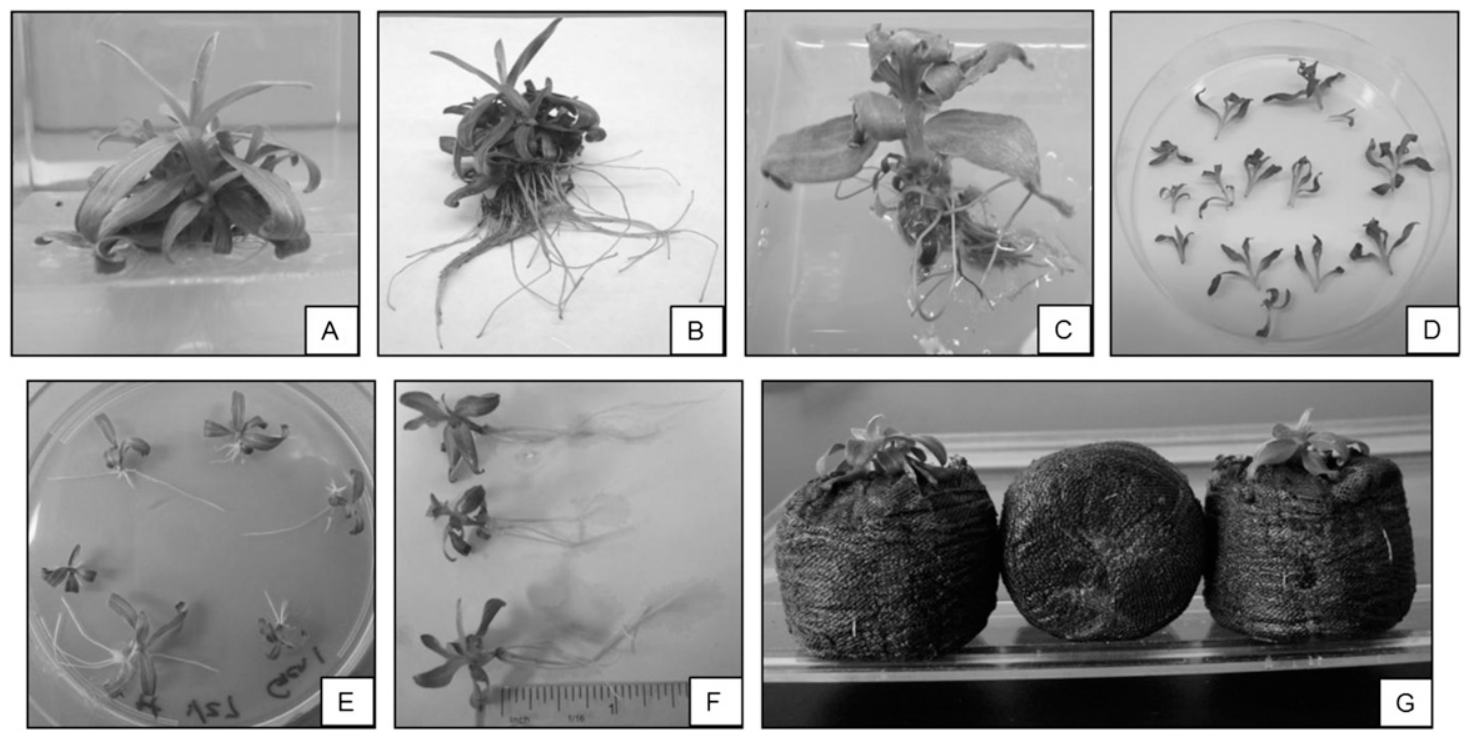

Fig. 3. In vitro multiplication of Pityopsis ruthii (A-C) plantlet before and after removal of lateral stems. (D) Lateral stem before culture on Murashige and Skoog medium. (E) Stems $7 \mathrm{~d}$ after removal. (F) Stems $14 \mathrm{~d}$ after removal. (G) Acclimated plantlets $28 \mathrm{~d}$ after removal. 

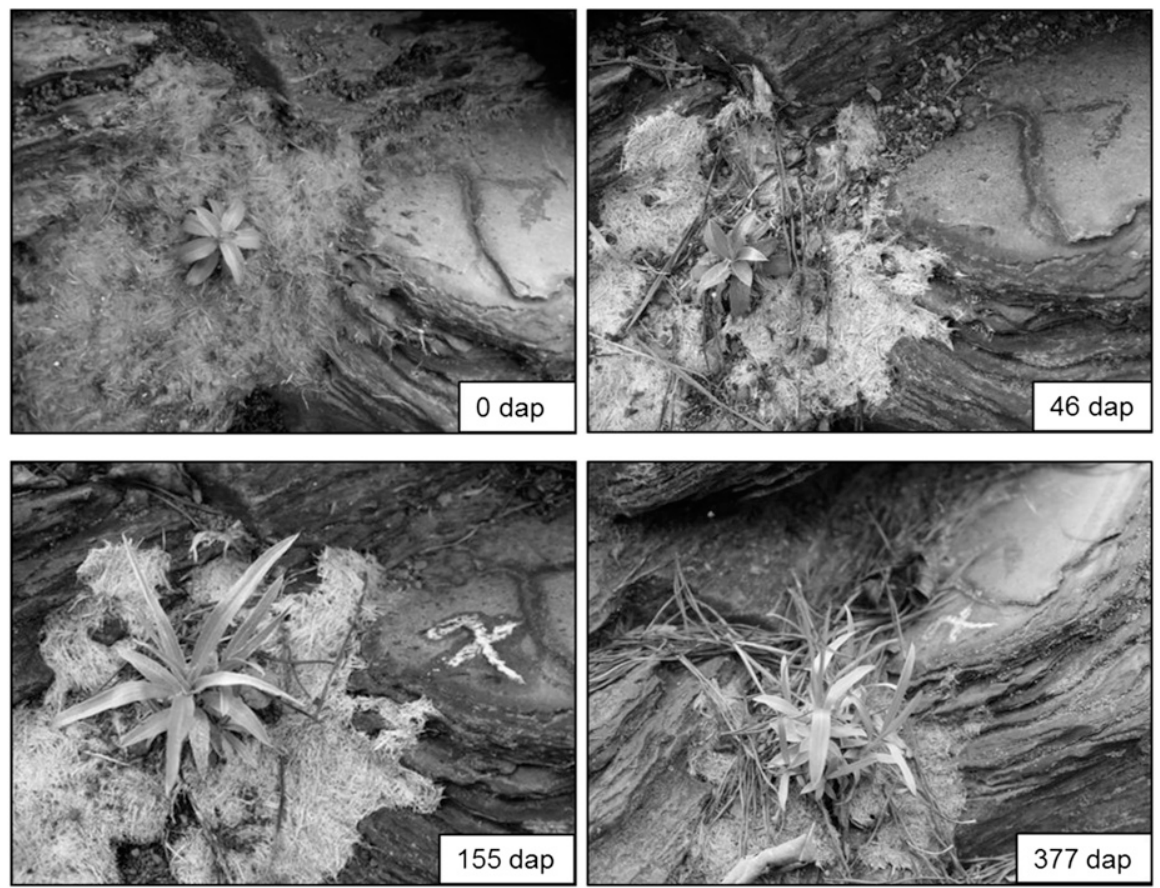

Fig. 4. Restoration of Pityopsis ruthii on the Ocoee River, Polk County, TN, at 0, 46, 155, and $377 \mathrm{~d}$ after planting (DAP).

golden aster populations are suffering from inbreeding depression caused by reduced genetic diversity or habitat degradation and are affecting germination, recruitment, viability, and/or vigor of seeds.

The lack of information on seed recruitment, habitat loss, and population structure coupled with high mortality of seedlings in Ruth's golden aster natural populations pose challenges to developing strategies to protect sustainability of these populations. Although in vitro regeneration protocols for Ruth's golden aster are available (Wadl et al., 2011), the costs associated with in vitro methodology are higher than for conventional propagation (Pence, 2011). The most economical method for biodiversity conservation of plants, in general, is the collection of vegetative cuttings and seeds (Reed et al., 2011). However, overreliance on vegetative cuttings can introduce genetic swamping into isolated populations through ex situ conservation programs (Kramer and Havens, 2009). Propagation of multiple wild-collected stem cuttings and in vitro-grown seedlings can limit the influence of a single genotype on study results and eliminate the potential influence of genetic swamping resulting from planting multiple clones of a single individual in population augmentations or reintroduction attempts.

The Asteraceae contains the largest number of listed endangered and threatened species with over 2500 (Pence, 2010; Walter and Gillett, 1998). Vegetative propagation of Centaurea tchihatcheffii (Asteraceae) using softwood stem cuttings treated with IBA and rooted in sand has been achieved (Ozel et al., 2006). Although the IBA concentration and rooting substrates used in our study were different, some similarities and differences should be noted. Similarly, we had a greater frequency of rooting when juvenile stems were used and conversely no cuttings rooted when sand was used as the rooting media. In vitro seed germination and multiplication methods for members of the Asteraceae have been described for Leontopodium nivale (Pace et al., 2009), Saussurea obvallata (Joshi and Dhar, 2003), Sericocarpus rigidus (Frey et al., 2007), and Symphyotrichum georgianum (Lynch et al., 2013). Comparisons between the multiplication rates in these studies and our results should be avoided because we did not use growth regulators for shoot multiplication. Similarly, comparisons of in vitro seed germination and contamination rates are difficult because the methodologies are different. However, Lynch et al. (2013) reported low rates of contamination for seeds of $S$. georgianum when the pappus remained and seeds were surface sterilized in $20 \% \mathrm{H}_{2} \mathrm{O}_{2}$. In contrast, we found high rates of contamination when the pappus remained regardless of bleach treatment used.

Previous efforts to establish Ruth's golden aster in a suitable, unoccupied habitat were unsuccessful. Cruzan and Beaty (1998) performed several experimental plantings using seeds, greenhouse-propagated seedlings, and basal rosettes that were excised from plants in the field and immediately planted in nearby crevices. In the first small study, 60 seeds and 16 basal rosettes were installed in a suitable habitat. After two growing seasons, two basal rosettes and no seedlings had survived. During the second study, 100 individual seeds and 50 transplanted seedlings were installed in the Spring of 1997 . No transplants and one plant originating from seed survived to October of that year.
Quantitative data were not used explain experimental failures, but the investigators plainly recognized the potential for drought stress and soil disturbance to negatively impact reintroduced plants. Some reintroduction plots containing both seeds and transplanted rosettes were augmented with a moistureretaining soil amendment at planting time. Subsequent site visits found the amended medium had swelled significantly, had become dislodged from the planting crevices, and had been washed away along with the propagules. Other treatments using sphagnum moss and netting to retain moisture and hold plants and seeds on-site were equally ineffective (Cruzan and Beaty, 1998).

Riparian zones are highly dynamic and reintroducing plants into habitats subject to frequent inundation and periodic drought is challenging and is of conservation concern (Homoya and Abrell, 2005; USFWS, 2008; Wells, 2012). Pooled survivorship of reintroduced seeds and plants of Symphyotrichum laurentianum (Asteraceae) to Prince Edward Island National Park, Canada, over a 2-year period was $52.8 \%$ (Atkinson and Lacroix, 2013). Although a larger, replicated study is needed to make definitive conclusions regarding the efficacy of BFM in aiding survival of transplanted Ruth's golden aster, the results from our study are encouraging with $73.6 \%$ pooled survivorship over 1 year. Theoretically, the use of BFM to anchor Ruth's golden aster into rock crevices where they naturally grow would increase resilience to flood scouring by holding the disturbed soil around the rooted plantlets and by maintaining higher soil moisture around treated individuals. The principal advantage of BFM over other anchoring/mulching methods, like those used by Cruzan and Beaty (1998), is that the material is mixed and applied as a slurry that binds to itself and the surrounding landscape. In the case of Ruth's golden aster, this allows for a seamless barrier that bridges the crevices containing rooted plantlets and adheres to the adjacent rock, thereby reducing the likelihood of failure during inundating flows. Our study describes for the first time conventional propagation of Ruth's golden aster through stem cuttings and in vitro seed germination and multiplication techniques that are viable options for the production of Ruth's golden aster plants for future conservation and recovery efforts. We have demonstrated that the reported protocols have been used to clone plants from the native habitat. The cloned plants have been used to establish ex situ collections of plants and conduct a successful preliminary reintroduction of plants into unoccupied habitat. This is an important step toward the conservation and recovery of Ruth's golden aster and should facilitate future reintroduction projects aimed at increasing the long-term survival of the species.

In conclusion, ex situ observations of $P$. ruthii propagated from stem cuttings and tissue culture suggests that both techniques are feasible for producing plants suitable for reintroduction and germplasm conservation. 
Optimum rooting of stem cuttings is achieved from vegetative stems as compared with flowering stems. The removal of the pappus from seeds of $P$. ruthii and bleach treatment is critical for establishment of sterile in vitro seedlings. The use of bonded fiber matrix as well as the development of the propagation protocol has broader implications for conservation of other narrow endemic plant species. A comprehensive microsatellite-based population genetics study is underway to determine population structure and to define conservation units for $P$. ruthii and the propagation and reintroduction methods described here will facilitate long-term conservation and restoration efforts for the species.

\section{Literature Cited}

Atkinson, K. and C. Lacroix. 2013. Evaluating reintroduction methods for the Gulf of Saint Lawrence aster (Symphyotrichum laurentianum) on Prince Edward Island. Botany 91:293-299.

Clebsch, E.E.C. and A. Sloan. 1993. Final report, contract between the University of Tennessee and the Tennessee Department of Environment and Conservation for the study of various aspects of the ecology and life history of the endangered plant species Ruth's golden aster (Pityopsis ruthii). Rpt. Tennessee Dept. Environ. Conservation.

Cruzan, M.B. 1998. Genetic markers in plant evolutionary ecology. Ecology 79:400-412.

Cruzan, M.B. 2001. Ecological genetics of Pityopsis ruthii: Final research report I. Reproductive ecology. Unpublished report. Tennessee Dept. Environ. Conservation Div. Natural Heritage.

Cruzan, M.B. and P. Beaty. 1998. Population biology of Ruth's golden aster (Pityopsis ruthii). Rpt. Tennessee Dept. Environ. Conservation Div. Natural Heritage ID-96-05937-6-00.

Cruzan, M.B. and J.C. Estill. 2001. Ecological genetics of Pityopsis ruthii: Final research report. II. Phylogeography. Unpublished report. Tennessee Dept. Environ. Conservation Div. Natural Heritage.

Farmer, R.E., Jr. 1977. Seed propagation of Heterotheca ruthii. Castanea 42:146-149.

Frey, B., C. Kempler, and D.L. Ehert. 2007. Micropropagation of White-top aster, Sericocarpus rigidus, a threatened species from the Garry
Oak ecosystem in British Columbia. Can. Field Nat. 121:40-45.

Fritsch, P. and L.H. Rieseberg. 1996. The use of random amplified polymorphic DNA (RAPD) in conservation genetics, p. 54-73. In: Smith, T.B. and R.K. Wayne (eds.). Molecular genetics approaches in conservation genetics. Oxford University Press, New York, NY.

Homoya, M.A. and D.B. Abrell. 2005. A natural occurrence of the federally endangered Short's goldenrod (Solidago shortii T. \& G.) [Asteraceae] in Indiana: Its discovery, habitat, and associated flora. Castanea 70:255-262.

Honnay, O., and H. Jacquemyn. 2007. Susceptibility of rare and common plant species to the genetic consequences of habitat fragmentation. Conservation Biol. 21:824-831.

Joshi, M. and U. Dhar. 2003. In vitro propagation of Saussurea obvallata (DC.) Edgew.-An endangered ethnoreligious medicinal herb of Himalaya. Plant Cell Rpt. 21:933-939.

Kessler, J.R., Jr. and G.J. Keever. 2007. Plant growth retardants affect growth and flowering of Coreopsis verticillata 'Moonbeam' J. Envir. Hort. 25:229-233.

Kramer, A.T. and K. Havens. 2009. Plant conservation genetics in a changing world. Trends Plant Sci. 14:599-607.

Les, D.H., J.A. Reinartz, and E.J. Esselman. 1991. Genetic consequences of rarity in Aster furcatus (Asteraceae), a threatened, self-incompatible plant. Evolution 45:1641-1650.

Lynch, S., R.K. Johnston, R.O. Determann, J.M Cruse-Sanders, and G.S. Pullman. 2013. Seed cryostorage and micropropagation of Georgia aster, Symphyotrichum georgianum (Alexander) Nesom: A threatened species from the southeastern United States. HortScience 48:750-755.

Murashige, T. and F. Skoog. 1962. A revised medium for rapid growth and bioassays with tobacco tissue cultures. Physiol. Plant. 15:473-497.

Ozel, C.A., K.M. Khawar, S. Mirici, O. Arslan, and S. Ozcan. 2006. Induction of ex vitro adventitious roots on softwood cuttings of Centaurea tchihatcheffii Fisch et. Mey using indole 3-butyric acid and $\alpha$-naphthalene acetic acid. Intl. J. Agr. Biol. 8:66-69.

Pace, L.G., A.A. Bruno, and L. Spanò. 2009. In vitro plant regeneration and clonal micropropagation of Leontopodium nivale (Ten.) Heut ex Hand.-Mazz. (Asteraceae). Plant Biosyst. 143:S12-S16.
Pence, V. 2011. Evaluating costs for the in vitro propagation and preservation of endangered plants. In Vitro Cell. Dev. Biol. Plant 47:176187.

Pence, V.C. 2010. The possibilities and challenges of in vitro methods for plant conservation. Kew Bull. 65:539-547.

Reed, B.M., V. Sarasan, M. Kane, E. Bunn, and V.C. Pence. 2011. Biodiversity conservation and conservation biotechnology tools. In Vitro Cell. Dev. Biol. Plant 47:1-4.

Semple, J.C. 2006. Treatment of Pityopsis, p. 222 228. In: Flora of North America Editorial Committee (ed.) Volume 20, Magnoliophyta: Asteridae, part 7: Asteraceae, part 2. Oxford University Press, New York, NY.

Sharrock, S. 2012. Global strategy for plant conservation. A guide to the GSPC all the targets, objectives and facts. Botanic Garden Conservation International, Richmond, UK.

Sloan, S.A. 1994. Allozyme variation within and between populations of Ruth's Golden Aster, Pityopsis ruthii (Small) Small. MS Thesis, Univ. of Tenn., Knoxville.

United States Fish and Wildlife Service. 1992. Ruth's golden aster recovery plan. Atlanta, GA.

United States Fish and Wildlife Service. 2008 Jesup's milk-vetch (Astragalus robbinsii var. jesupii), 5-year review: Summary and evaluation. U.S. Fish and Wildlife Serv., Concord, $\mathrm{NH}$

United States Fish and Wildlife Service. 2012. Ruth's golden aster (Pityopsis ruthii), 5-year review: Summary and evaluation. U.S. Fish and Wildlife Serv., Cookeville, TN.

Wadl, P.A., A.J. Dattilo, L.M. Vito, and R.N Trigiano. 2011. Shoot organogenesis and plant regeneration in Pityopsis ruthii. Plant Cell Tissue Organ Cult. 106:513-516.

Walter, K.S. and H.J. Gillett. 1998. 1997 IUCN red list of threatened plants compiled by the world conservation monitoring centre, IUNC. The World Conservation Union, Gland, Switzerland, and Cambridge, UK.

Wells, E.F. 2012. Reintroduction of federally endangered harperella (Harperella nodosum Rose) in flood-prone, artificial, and natural habitats. Castanea 77:146-157.

White, A.J. 1977. An autecological study of the endangered species, Heterotheca ruthii (Small) Harms. MS thesis, Univ. Tennessee, Knoxville, TN. 